\title{
Correlation between diffuse EEG abnormalities and cerebral atrophy in senile dementia
}

\author{
DUSAN STEFOSKI, DONNA BERGEN, JACOB FOX, FRANK MORRELL, \\ MICHAEL HUCKMAN, AND RUTH RAMSEY
}

\author{
From the Department of Neurological Sciences and Department of Diagnostic Radiology, \\ Rush-Presbyterian-St. Luke's Medical Center, Chicago, Illinois, USA
}

SYNOPSIS Thirty-five elderly patients were investigated because of clinical signs of dementia. The presence of diffuse cerebral atrophy, and its severity, were determined by the use of computed tomography (CT scan). All of the patients were also examined by electroencephalography (EEG), and the presence of diffuse abnormalities, especially diffuse slowing, was noted. Specifically, patients with normal or near-normal EEGs were compared with those with severe diffuse slowing. No correlation between the presence or severity of diffuse EEG abnormalities and the degree of cerebral atrophy as measured by CT scan was found. Though the EEG is clearly identifying physiological dysfunction of nerve cells in demented patients it does not appear to be a reliable tool for the prediction of diffuse cerebral atrophy in this population.

Senile dementia in association with diffuse cerebral atrophy is one of the problems commonly encountered by the clinical neurologist. In numerous studies the EEG of demented individuals was found to undergo significant changes. However, few studies have been reported which attempt to correlate the degree of cerebral atrophy with the severity of the EEG abnormalities in mentally deteriorating aging persons (MundyCastle et al., 1954; Weiner and Schuster, 1956; Busse and Wang, 1965; Muller and Kral, 1967).

The present study was designed to explore the correlation between these two variables in order to assess whether the EEG might be a reliable tool for the detection of cerebral atrophy in the elderly demented patient.

\section{METHODS}

Thirty-five patients over 59 years of age were among a larger group hospitalized on the basis of having clinical signs of dementia. Senile dementia was

\footnotetext{
${ }^{1}$ Address for reprint requests: Dr Donna Bergen, Department of Neurological Sciences, Rush-Presbyterian-St. Luke's Medical Center, 1753 West Congress Parkway, Chicago. Illinois, 60612, USA.

(Accepted 19 March 1976.)
}

defined as the gradual onset of intellectual deterioration after the age of 59 years. Those patients with a past history of strokes or major focal findings on the neurological examination were excluded. Patients who fulfilled these criteria and who were studied with both computed tomography and electroencephalography form the basis of the study. In all these patients, diagnoses such as brain tumour, hypothyroidism, hydrocephalus, or other potentially treatable causes of dementia were excluded. It is assumed that most had Alzheimer's disease, though some may have had multiple small cerebrovascular accidents in spite of the lack of focal findings.

Electroencephalograms (EEGs) were recorded from each patient, using the standard 10-20 method of electrode placement, on 16-channel ElemaSchönander apparatus, using seven different electrode montages (five bipolar and two referential), performing photic stimulation as well as hyperventilation whenever the patient's condition allowed it. Patients with either normal records or generalized abnormalities were included in the study group. Since the specific purpose of this study was to explore the possible correlations between generalized EEG changes and diffuse cerebral atrophy, patients with focal EEG abnormalities were excluded from the study group.

The EEGs of these 35 patients were divided into three groups. Group A consisted of normal records. 
Group B consisted of records considered to be mildly abnormal; EEGs in which $5-7 \mathrm{~Hz}$ theta activity made up at least $10 \%$ of the waking background activity were included in this category. Records in which at least $10 \%$ of the waking background rhythms consisted of frequencies equal to or less than $4 \mathrm{~Hz}$ were placed in group $\mathrm{C}$, and considered to be severely abnormal.

In each patient, the presence and amount of cerebral atrophy was determined by computed tomography (CT scan) of the head. Computed tomography (CT scanning) is a new non-invasive radiological technique which allows accurate delineation of ventricular configuration and size (Hounsfield, 1973). Ventricular enlargement as measured by CT scan was used as a measure of diffuse cerebral atrophy, using a method devised and previously applied by Huckman et al. (1975). In most cases EEGs were recorded within several days of the CT scan, so that for the purposes of this study the two tests may be considered to have been done at virtually the same stage in the evolution of the dementing process in each patient. The dimensions of the lateral ventricles were used to assess cerebral atrophy. Although the CT scan also revealed varying degrees of enlargement of cortical sulci in all patients included in the study, ventricular size was used exclusively in this study as it is the most reliable and reproducible measurement of atrophy obtainable from the CT scan (Huckman et al., 1975). The following measurements, in millimetres, were made from Polaroid photographs of the CT scan by neuroradiologists who were unaware of the EEG findings and clinical data.

A. The distance between the most lateral portion of each of the frontal horns (Fig. 1).

B. The width of the lateral ventricles in the region of the caudate nuclei, that being the width of the two lateral ventricles just anterior to the third ventricle (Fig. 1).

The $\mathrm{A}$ and $\mathrm{B}$ measurements were added together to give a single measure of ventricular size. The actual dimensions in centimetres can be obtained by multiplying this number by 3.63. Previous work suggests that a combined ventricular size of $15 \mathrm{~mm}$ or less, as measured in this fashion on the Polaroid photograph, may be considered normal in patients below the age of 60 years. Above that age up to $20 \mathrm{~mm}$ may be considered within the broad normal range (Huckman et al., 1975).

A normal CT scan is shown in Fig. 2. A CT scan showing enlarged lateral ventricles and large cortical sulci is reproduced in Fig. 3.

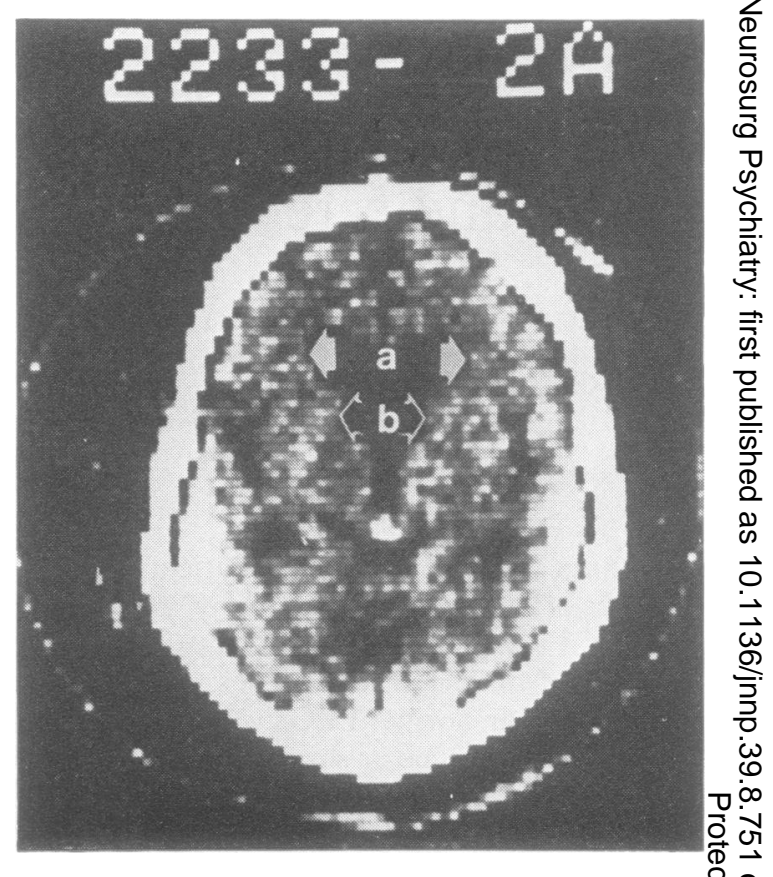

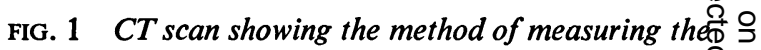
size of lateral ventricles.

\section{RESULTS}

Eight $(22.9 \%)$ out of 35 patients with dementia irôㅂ $\vec{\varphi}$ this study group had a normal EEG, $14(40 \%)$ had oे mild generalized abnormality, and $13(37.1 \%)$ had severe generalized abnormality. The mean ventricular size was computed for patients in each EEG group (Table 1). There was no significant difference between mean ventricular size of patients in group $\mathbf{A}$ (normal EEG) and those in group $\mathrm{C}$ (severely abnormal EEG). Since mild slowing of EEG frequencies is commonly seen in the aged population, we also combined groups $\mathrm{A}$ and $\mathrm{B}$ and compared this larger number with group $\mathrm{C}$. Again no significant difference in ventricular size was seen. In fact, the mean ventricular size was almost exactly the same in all three groups.

TABLE 1

MEAN VENTRICULAR SIZE IN VARIOUS EEG GROUPS

\begin{tabular}{lrc}
\hline EEG group & $n$ & $\begin{array}{c}\text { Mean ventricular size } \\
(\mathrm{mm})\end{array}$ \\
\hline A & 8 & 20.50 \\
A and B & 22 & 20.59 \\
C & 13 & 21.00 \\
\hline
\end{tabular}



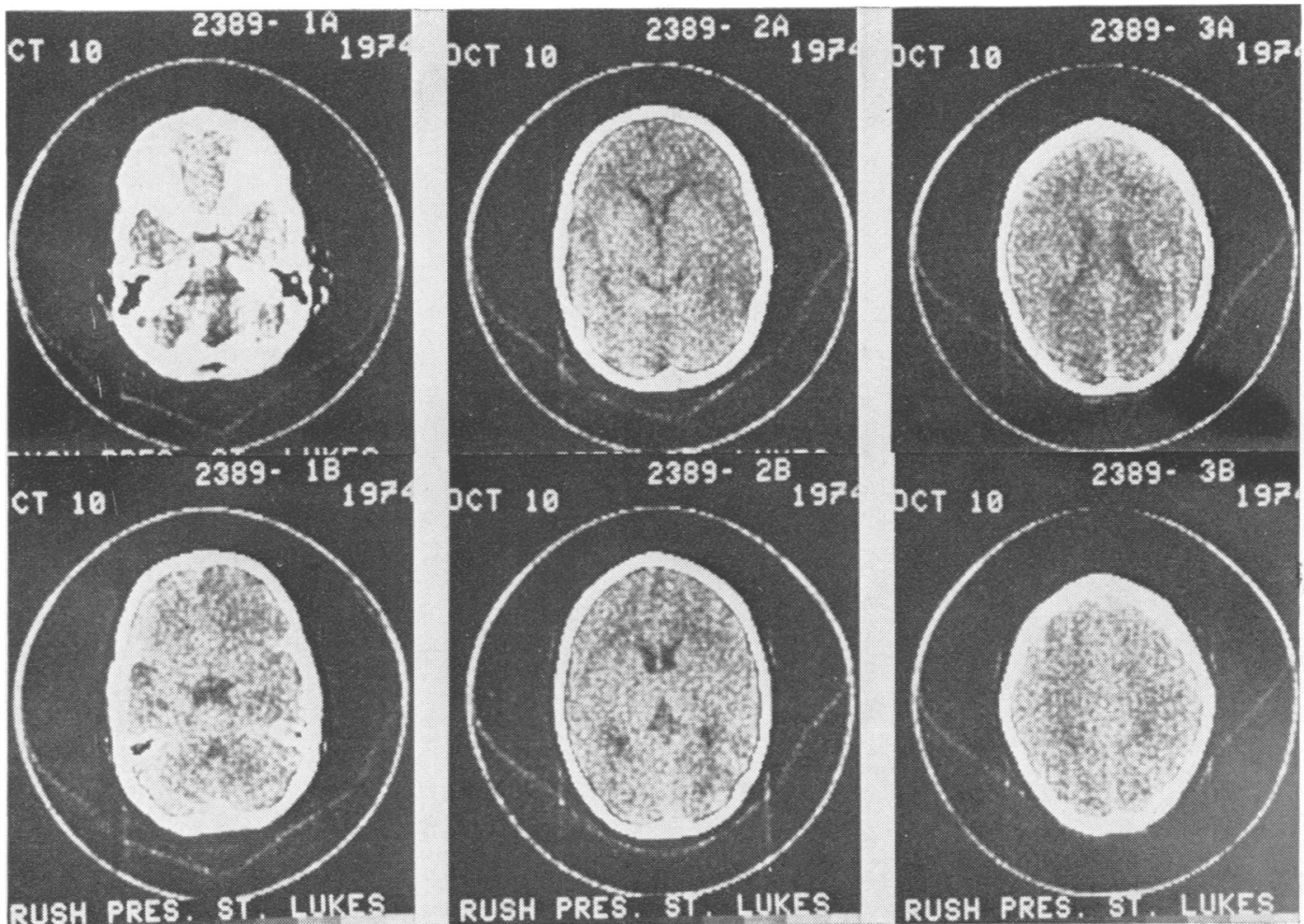

FIG. 2 CT scan showing normal brain.

TABLE 2

MEAN AGE IN VARIOUS EEG GROUPS

\begin{tabular}{lrc}
\hline EEG group & $n$ & $\begin{array}{c}\text { Mean age } \\
(\boldsymbol{y r})\end{array}$ \\
\hline A & 8 & 72.6 \\
A and B & 22 & 73.8 \\
C & 10 & 72.5 \\
\hline
\end{tabular}

TABLE 3

MEAN VENTRICULAR SIZE IN VARIOUS EEG GROUPS SEPARATED ACCORDING TO SEX

\begin{tabular}{lcc}
\hline $\begin{array}{c}\text { EEG group } \\
\text { (males) }\end{array}$ & $n$ & $\begin{array}{c}\text { Mean ventricular size } \\
(\mathbf{m m})\end{array}$ \\
\hline A & 6 & 21.5 \\
A and B & 14 & 22.0 \\
C & 10 & 21.8 \\
\hline
\end{tabular}

Since the EEG is said to become slower with increasing age (Obrist, 1954), we calculated the mean age of patients in each EEG group (Table 2). Again, the difference between groups $A$ and $B$ compared with group $\mathrm{C}$, and the difference between group $\mathbf{A}$ alone compared with group $\mathrm{C}$, were not significant. The mean ages for each group are almost identical.

The sex of the patient has been shown to be related to ventricular size, normal males having larger ventricles than females of the same age (Obrist, 1954). Thus, we segregated the male patients from our population and calculated and compared ventricular size for each EEG group (Table 3). Again, there was no significant difference when group $\mathbf{A}$ alone or group $\mathbf{A}$ and $\mathbf{B}$ together were compared with group $\mathrm{C}$. Females alone were not compared because of the small numbers. 

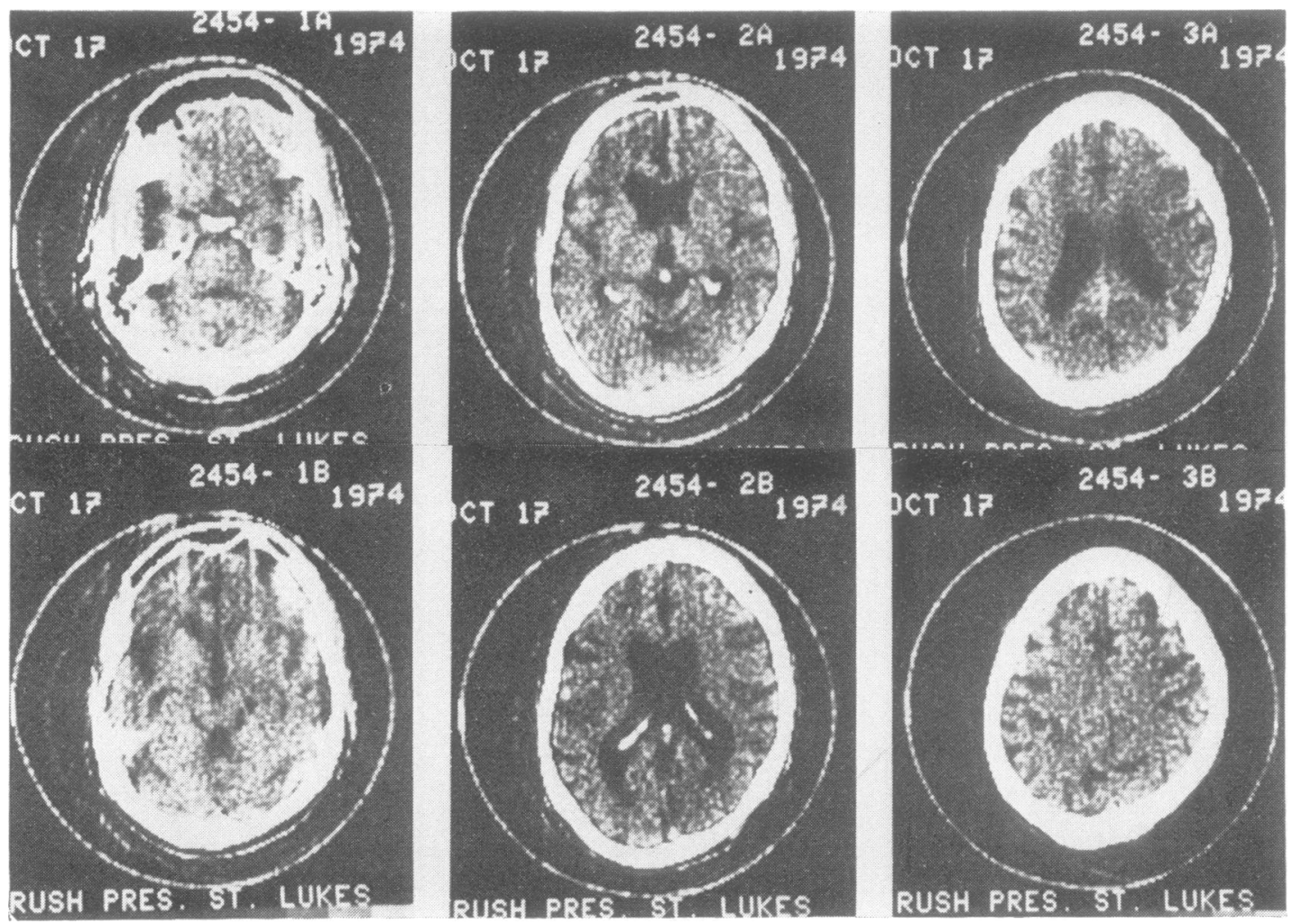

FIG. 3 CT scan showing brain with marked ventricular enlargement and atrophic sulci.

\section{DISCUSSION}

Our results show that there is, in fact, no direct correlation between cerebral ventricular size and diffuse EEG abnormalities. The average ventricular size of our demented patients with normal EEGs ( $20.5 \mathrm{~mm}$ on CT scan Polaroid points) was almost exactly the same as the average ventricular size of patients with mild $(20.59 \mathrm{~mm})$ or severe $(21.00 \mathrm{~mm})$ diffuse slowing on EEG.

Our study reveals that more than three-quarters $(77.1 \%)$ of the group studied had abnormal EEGs (of mild and severe degree). Other investigators (Levin and Greenblatt, 1948; Trowbridge and Finley, 1972) have also evaluated EEG abnormalities in patients with ventricular dilatation (as measured by pneumoencephalography). Levin and Greenblatt (1948) reported that only $44 \%$ of their cases had an abnormal EEG. Trow- bridge and Finley (1972) found abnormal EEGs to be about as frequent in cases with normal as in those with abnormal pneumoencephalograms. Both these groups reported that slow wave electrographical abnormalities were more common in cases with ventricular dilatation compared with those with cortical atrophy. These studies, however, are not comparable with ours as they included patients in every age group (including children) and patients with ventricular dilatation from a wide variety of causes. In contrast, our patients formed a homogeneous group, all with clinical signs of dementia and an age range of 59 to 82 years (average 73 years).

Why the EEGs in some demented patients in our series are normal and others abnormal remains unexplained. Identifiable metabolic abnormalities were seen in only a few patients, and in none of these cases did the abnormalities seem 
of sufficient magnitude to cause generalized EEG abnormalities.

Some investigators have claimed that the degree of EEG abnormality reflects the degree of intellectual impairment in demented patients (Gordon and Sim, 1967). Others have shown that diffuse brain atrophy correlates with clinical signs of dementia in senile and presenile patients (Tomlinson et al., 1970; Kaszniak et al., 1975). These are separate questions, still not definitely answered, which our study was not designed to consider. Similarly, since the purpose of this study was to assess the relationship between diffuse EEG abnormalities and cerebral atrophy, patients with focal EEG pathology were excluded.

The data presented here do show that the degree of slowing on EEG is of no value in determining the presence or severity of cerebral atrophy in senile dementia. The apparent discrepancy between these two variables in senile dementia is understandable since the EEG reflects activity of functioning (not necessarily normal) nerve cells while ventricular dilatation as measured by CT scan indicates loss of brain tissue. Thus, it seems reasonable to conclude that generalized EEG abnormalities seen in demented senile individuals result from functional impairment rather than structural damage per se. It is also possible that subtle metabolic abnormalities, undetectable by present methods and not necessarily correlated with the presence of cerebral atrophy, may cause the EEG changes seen in the demented.

REFERENCES

Busse, E. W., and Wang, H. S. (1965). The value of electroencephalography in geriatrics. Geriatrics, 20, 906-924.
Gordon, E. B., and Sim, M. (1967). The EEG in presenile dementia. Journal of Neurology, Neurosurgery, and Psychiatry, 30, 285-291.

Hounsfield, G. N. (1973). Computerized transverse axial scanning (tomography) 1. Description of system. British Journal of Radiology, 46, 1016-1022.

Huckman, M. S., Fox, J. H., and Topel, J. L. (1975). Criteria for the diagnosis of brain atrophy by computerized tomography. Radiology, 116, 85-92.

Kaszniak, A. W., Garron, D. C., and Fox, J. H. (1975). Relation between dementia and cerebral atrophy as measured by computerized tomography. (Abstract.) Neurology (Minneap.), 25, 387.

Levin, S., and Greenblatt, M. (1948). Electroencephalography in cases with cortical atrophy and ventricular dilation. American Journal of Psychiatry, 105, 220-224.

Muller, H. F., and Kral, V. A. (1967). The electroencephalogram in advanced senile dementia. Journal of the American Geriatric Society, 15, 415-426.

Mundy-Castle, A. C., Hurst, L. A., Beerstecher, D. M., and Prisloo, T. (1954). The electroencephalogram in the senile psychoses. Electroencephalography and Clinical Neurophysiology, 6, 245-252.

Obrist, W. D. (1954). The EEG of normal aged adults. Electroencephalography and Clinical Neurophysiology, 6, 235-244.

Tomlinson, B. E., Blessed, G., and Roth, M. (1970). Observations on the brains of demented old people. Journal of the Neurological Sciences, 11, 205-242.

Trowbridge, E. J. Jr, and Finley, K. H. (1972). The electroencephalogram and pneumoencephalogram in non-focal neurological disorders. American Journal of Roentgenology and Radium Therapy, 47, 699-702.

Weiner, H., and Schuster, D. B. (1956). Electroencephalogram in dementia: some preliminary observations and correlations. Electroencephalography and Clinical Neurophysiology, 8, 479-488. 